\title{
Virtue and care ethics \& humanism in medical education: a scoping review
}

\author{
David J. Doukas ${ }^{1 *}$, David T. Ozar ${ }^{2}$, Martina Darragh ${ }^{3}$, Janet M. de Groot ${ }^{4}$, Brian S. Carter ${ }^{5}$ and Nathan Stout ${ }^{1}$
}

\begin{abstract}
Purpose: This scoping review explores how virtue and care ethics are incorporated into health professions education and how these factors may relate to the development of humanistic patient care.

Method: Our team identified citations in the literature emphasizing virtue ethics and care ethics (in PubMed, NLM Catalog, WorldCat, EthicsShare, EthxWeb, Globethics.net, Philosopher's Index, and ProQuest Central) lending themselves to constructs of humanism curricula. Our exclusion criteria consisted of non-English articles, those not addressing virtue and care ethics and humanism in medical pedagogy, and those not addressing aspects of character in health ethics. We examined in a stepwise fashion whether citations: 1) Contained definitions of virtue and care ethics; 2) Implemented virtue and care ethics in health care curricula; and 3) Evidenced patient-directed caregiver humanism.
\end{abstract}

Results: Eight hundred eleven citations were identified, 88 intensively reviewed, and the final 25 analyzed in-depth. We identified multiple key themes with relevant metaphors associated with virtue/care ethics, curricula, and humanism education.

Conclusions: This research sought to better understand how virtue and care ethics can potentially promote humanism and identified themes that facilitate and impede this mission.

Keywords: Virtue ethics, Care ethics, Humanism, Medical education, Medical ethics

\section{Background}

Health care education in the last two decades has led many to grapple with the means of better understanding professionalism in medical education [16]. The Project to Rebalance and Integrate Medical Education (PRIME) [29, 33-35] framed those aspects of knowledge and skills that lead to professionalism formation. PRIME characterized a construct for professionalism in which medical ethics

\footnotetext{
*Correspondence: david.doukas@Tulane.edu

${ }^{1}$ Department of Family and Community Medicine, James A. Knight Chair of Humanities and Ethics in Medicine, Program in Medical Ethics and Human Values, Tulane University School of Medicine, 1430 Tulane Ave, \#8033, New Orleans, LA, USA

Full list of author information is available at the end of the article

These data were presented from the podium at both the 2019 Annual

Meeting of the American Society for Bioethics and Humanities, and the

2019 Annual Meeting of the Academy for Professionalism in Health Care
}

(including both virtue and care ethics), fine arts, medical history, and narrative were asserted as requisite in the knowledge domain needed for resultant humanistic behavior. Understanding how these approaches to ethics inform health care curricula and humanism, we can examine the connections between them that others have postulated [30, 46, 52, 54]. This project aims to identify published studies that define virtue and care ethics, then use these concepts in medical curricula, and identify their association with humanistic behavior.

We seek to identify health care curricula using virtue and care ethics and how humanistic behavior is thereby promoted. Virtue ethics is one of three major ethical theories on how one should respond to moral quandaries. Virtue ethics emphasizes how optimizing those aspects of moral character will predispose one to behave in an ethical manner and has been frequently 
described as core to professionalism [47]. The other ethical theories commonly used in medical education are Deontology, from which classical duties of Respect for Persons and Justice in contemporary bioethics are grounded, and Consequentialism, which evaluates the outcomes of one's actions and includes the principles of Beneficence and Non-maleficence [27]. Virtue ethics includes moral reasoning, altruism, beneficence, honesty, and integrity and is thought to motivate professional behavior when enacted through practice [41].

Care ethics at its core is relational $[40,51]$ and thus differs from virtue ethics where care may be a virtue that individuals seek to enhance [42]. The concept of care is both core to and distinct from care ethics. In the context of healthcare, care ethics acknowledges that caring occurs in unequal relationships, in which one is more vulnerable and receives care [31]. Overall, care is described as co-constituted [42], with moral reasoning occurring in the context of relationships, incorporating emotion. Care ethics was developed, in part, in opposition to [39], or in some authors, as a crucial complement to, deontological and consequentialist theories $[36,45,50]$.

The Gold Foundation has had a pervasive educational presence in medical schools, with chapters influencing education in 172 North American and Caribbean allopathic and osteopathic medical schools. For an operational definition of humanism, we cite that offered by the Arnold P. Gold Foundation: "Humanism in healthcare is characterized by a respectful and compassionate relationship between physicians, as well as all other members of the healthcare team, and their patients. It reflects attitudes and behaviors that are sensitive to the values and the cultural and ethnic backgrounds of others" [38]. The goal of this study was to better understand how virtue and care ethics were used in medical curricula to advance the valuable role of humanism in health care. Our search was based on authors using the term "humanism."

As the Liaison Committee on Medical Education (LCME) requires that all medical schools have medical ethics and human values as part of their undergraduate curricula, this scoping review is poised to identify how such current virtue and care ethics teaching is put into effect with varying curricula, and then connected with learner humanistic behavior [44]. Our effort aims to identify curricular implementation of virtue and care ethics and their contribution to learner humanism, as there has not been a prior scoping review on this topic. Hence, our Research Question was formulated as: How has virtue and care ethics been implemented in medical curricula, and how is it related to learner humanism in the medical literature?

\section{Method}

We emulated the Scoping Review method articulated by Levac [43] to evaluate and collate information found on virtue and care ethics in medical education, then analyze relevant themes, and make note of significant metaphors that then lend themselves to our research question [26, 28, 43]. We first identified our research question, identified relevant citations, extracted data from the literature, and collated and summarized our results. We examined publications with three areas of interest: virtue and care ethics, their incorporation into medical curricula, and any description of humanistic behavior as an outcome. The search strategy was developed with the assistance of a university librarian (MD) and adapted to each database. We conducted a search in PubMed with the following:

(("Virtues" [Mesh] OR virtues OR "virtue ethics" OR Caring [Mesh] OR "care ethics") AND ("Humanism"[Mesh] OR humanism) AND (Education, medical [Mesh] OR "medical education" OR professionalism)).

Our team identified the literature in ethics highlighting those aspects with an emphasis on Virtue Ethics and Care Ethics, first in PubMed (1972 -). Despite using the Boolean "OR" for keywords and PubMed Mesh terms for maximum inclusivity, we noted a grave paucity of articles with our first PubMed search query. Thereafter, we employed PubMed's unique database feature of full text searching of our search terms within the abstracts of each identified citation. As shown in Fig. 1, we broadened our search in the following databases NLM Catalog (1993 -), World Cat (1997 -), EthicsShare (1984 -), EthxWeb (1974-2011), Globethics.net (2004 -), Philosopher's Index (1986 -), and ProQuest Central (1986 -), which incrementally added to the critical mass of resultant articles (by MD). Searches were initiated with PubMed on December 19, 2017, with subsequent stepwise additions utilizing the other identified databases through October 3, 2018.

Our exclusion criteria consisted of: non-English articles, those not addressing the use of virtue and care ethics toward humanism in medical curricula, and those not addressing aspects of character in health ethics.

We read and analyzed eligible articles in a stepwise fashion, considering iteratively the following three requisite considerations "Does this paper...:"

1. Have a well-accepted definition of virtue or care ethics? (We characterized each of these broadly and included any paper that prioritized the development of character or of caring relationships in their conception of medical ethics/values.) 


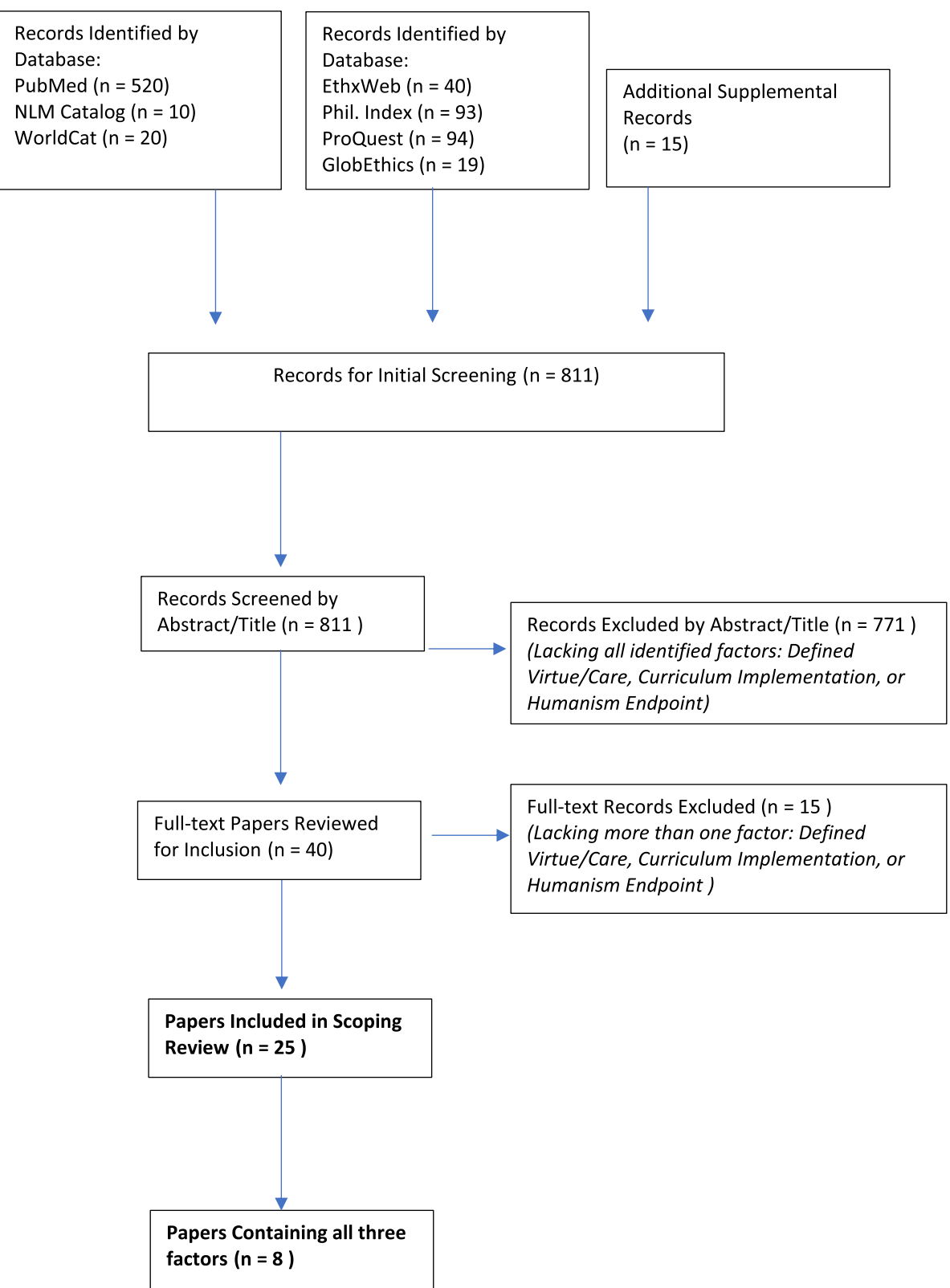

Fig. 1 Search Algorithm

2. Describe how virtue or care ethics are implemented in a healthcare curriculum?

3. Describe curricular efforts that contribute to patientcentered caregiver humanism?

Five hundred twenty articles were identified and evaluated using PubMed, with other ancillary databases yielding 246 additional articles, and 15 supplemental papers considered through citation referral yielding a total of 811 papers being screened. Team members DD, DO,
MD, JdG, and $B C$ evaluated the titles and abstracts of all papers. An initial review found 88 papers having at least one of the three sought factors. Next, papers were included only if at least two of the three factors were present: definition, curricular inclusion, and evidence of humanistic behavior as an outcome. The resultant 40 relevant papers were subjected to intense analysis by each team member. Each paper was scored on a four-level relevance scale (none, minimal, moderate, and high). Inclusion was based on the majority of team members scoring 
the article as moderate or high. Each team member identified relevant themes and metaphors that were then discussed by conference call pertaining to virtue/care ethics, curricula, and humanism education. Differences in scoring of these 40 papers were minimal and negotiated by all team members via conference call, until we achieved consensus on 25 papers.

\section{Results}

As depicted in Fig. 1, a total of 811 papers were evaluated, with subsequent Abstract full text search analysis identifying 25 papers deemed relevant in at least two of the three domains, and eight papers had all three factors under consideration. The factor that was most often missing was evidence of an implemented curriculum - we have indicated in bold on our Resultant Publication list those eight papers containing all three factors. Our practical decision to conduct detailed analysis of all 25 papers was based on the relative lack of articles containing all three factors, and it was noted that 17 articles lacking an implemented curriculum either proposed a curriculum or argued for curricular change.

The distinctive quality of these eight papers is that each lays a foundation of the conceptual framework of either virtue or care ethics and builds upon that basis with a curriculum that identifies humanistic outcomes. These papers emphasize multiple venues for virtue or care ethics - in undergraduate and graduate medical education, as well as in faculty development promoting mentorship - and as such, provide instructive templates towards future curricular development in this area.

The 25 articles range in date from 1994 to 2017, starting in proximity to when Gold Foundation Humanism efforts to foster humanism began and flourished, and when professionalism as a competency was introduced in US medical education assessment with one publication cluster noted in 2005-2009, and another cluster in 2015-2016. The journal Academic Medicine had the largest number of publications, with the Journal of Medical Ethics following, and then a distribution between other medical ethics and health service journals and publishing houses. We next proceeded to identify relevant themes.

\section{Themes}

DD and NS developed a draft set of themes that emerged and were negotiated on multiple readings of the 25 papers cited, which were subsequently refined with JdG and $\mathrm{BC}$, resulting in nine distinctive themes and four side issues in these papers (Table 1). These themes were: Altruism, Development of Virtuous Traits, Relationships, Dissonance/Virtue versus Principlism, Care as a Virtue, Praxis in Humanistic Behavior, Role Modeling, Pedagogy, and The Culture of Medicine/The Hidden Curriculum.
Additionally, there were four significant Noteworthy Considerations that were identified and were coherent but not centrally on point as a theme of cultivating virtue/care ethics and humanistic behavior (Table 2). These considerations consisted of Professionalism/Professional Formation, Narrative, the Use of Learning Communities, and the Need to Prevent Burnout.

The themes of Altruism, Development of Virtuous Traits, and Care as a Virtue are all related to the development of character in ethics within the educational process. The Altruism papers concentrated on perspectives that altruism is a prevailing virtue in medicine, often linked to the caring enterprise of healing [12]. Altruism was posited as running deeply such that this personal virtue can also be institutional, uniting the ideals of professional behavior [7]. Some propose that communities of learning should be cultivated, focusing on altruism to encourage humanism [23]. Altruism was considered a key virtue to counter negative influences in medical culture (discussed below) [14] Altruism also conceptually questioned: Can and should giving of oneself be so great as to allow self-sacrifice? [23].

The Development of Virtuous Traits theme appeared most commonly in our analysis, focusing on how virtue integrates health care values into the practice of medicine through a social contract [12]. The profession of medicine promotes virtues advancing professional conduct and patient healing [16]. Medical pedagogy in virtue and care ethics both identify aspects of character central to patient care [23]. Understanding virtue ethics may assist learners in better understanding ethical issues in healthcare, and thereby support development of humanistic behavior [7]. Virtue and care ethics helps the learner to utilize "internalized values," and incorporates emotion with cognition and complements other ethics teaching [15]. Promoting virtue calls for sound role-modeling by educators [14].

The Care as a Virtue theme addresses the concept of caring as being an augmenting factor to virtue ethics by incorporating emotion [11]. With this perspective, care helps to reveal the type of humanistic practices that learners might strive for, and how education should focus on caring to amplify the healing process [11]. The relationship of care to medicine is thought to be conveyed by way of love, connection, and caring through empathy [22]. Being a caring person was cited as an important attribute of highly influential educators of clinicians [6]. Often, care was coupled with other virtues such as altruism, compassion, and empathy in its explication in promoting humanism [20].

The theme of Dissonance/Virtue versus Principle describes how traditional deontological and consequentialist approaches to ethics in medical school can conflict with virtue and care ethics frameworks in such a way that 


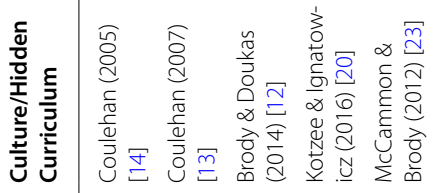

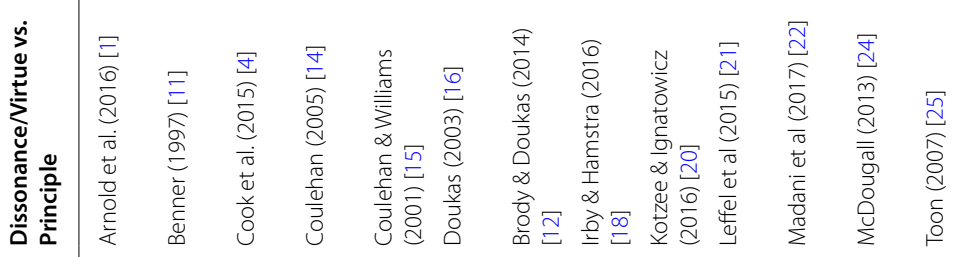

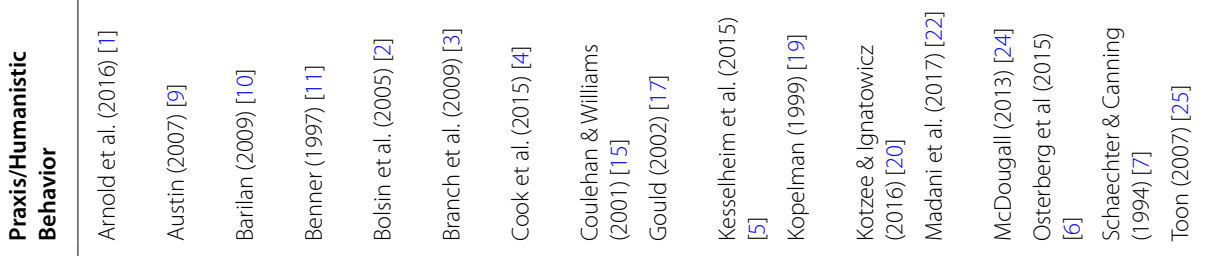

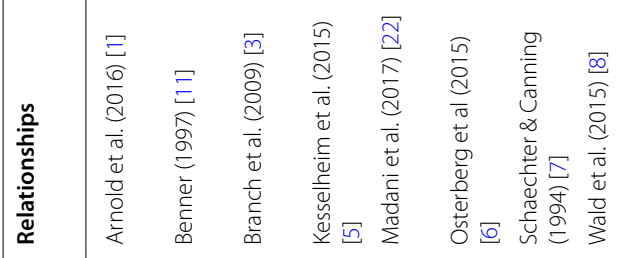

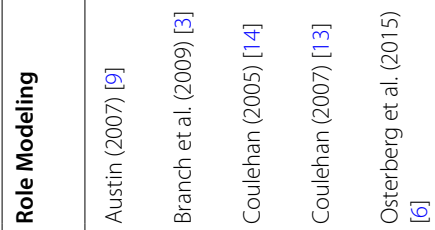

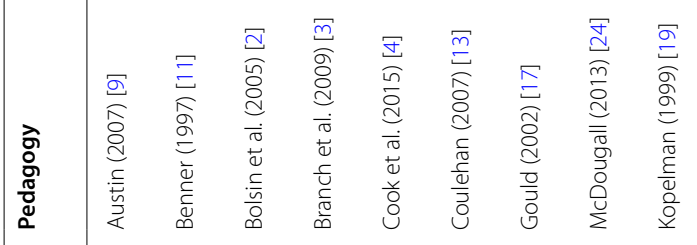

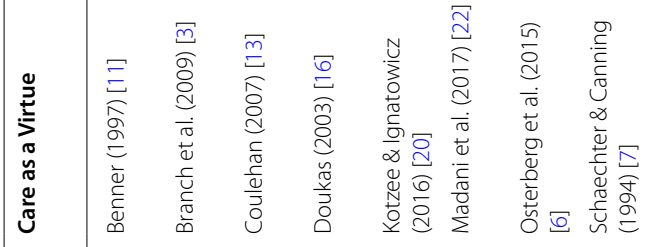

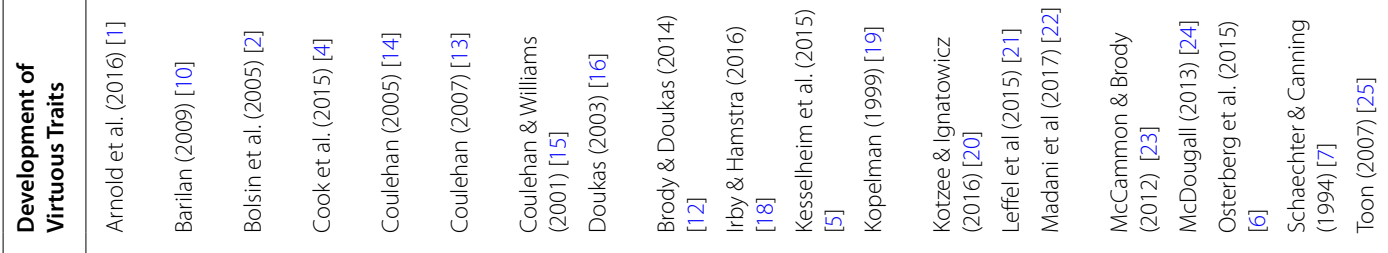

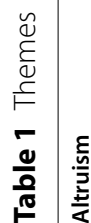

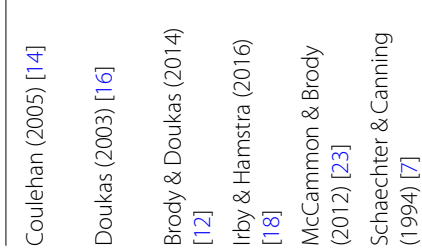


Table 2 Noteworthy Considerations

\begin{tabular}{|c|c|c|c|}
\hline Narrative & Prevention of Burnout & Learning Communities & $\begin{array}{l}\text { Professionalism/Professional } \\
\text { Formation }\end{array}$ \\
\hline Arnold et al. (2016) [1] & Kesselheim et al. (2015) [5] & Branch et al. (2009) [3] & Barilan (2009) [10] \\
\hline Austin (2007) [9] & & Osterberg et al. (2015) [6] & Benner (1997) [11] \\
\hline Coulehan (2005) [14] & & Schaechter \& Canning (1994) [7] & Bolsin et al. (2005) [2] \\
\hline Coulehan (2007) [13] & & & Coulehan (2005) [14] \\
\hline Osterberg et al. (2015) [6] & & & Coulehan (2007) [13] \\
\hline Schaechter \& Canning (1994) [7] & & & Coulehan \& Williams (2001) [15] \\
\hline Toon (2007) [25] & & & Doukas (2003) [16] \\
\hline \multirow[t]{9}{*}{ Wald et al. (2015) [8] } & & & Brody \& Doukas (2014) [12] \\
\hline & & & Irby \& Hamstra (2016) [18] \\
\hline & & & Kopelman (1999) [19] \\
\hline & & & Leffel et al (2015) [21] \\
\hline & & & Madani et al. (2017) [22] \\
\hline & & & McCammon \& Brody (2012) [23] \\
\hline & & & Osterberg et al. (2015) [6] \\
\hline & & & Schaechter \& Canning (1994) [7] \\
\hline & & & Wald et al. (2015) [8] \\
\hline
\end{tabular}

they may seem to ignore or overlook the value of character or caring relationships among those with unequal power within medical ethics [16]. Some call for a need to segregate the teaching of principles in medical ethics from aspects of virtue and care ethics [14]. Concepts of care and character are very different in the minds of students than the notion of duties and obligations [15]. Virtue ethics focuses on how character promotes traits that allow a person to be a better healer whereas respect for autonomy is concerned with what one owes to another person as a right [16]. Some argue that virtue ethics is a better means for analyzing ethical issues in healthcare than Principlism, leading to better acquisition of humanistic behavior [20]. The complementary nature of these teachings to one another is cited to augment each other [22]. It has been suggested that learners ought to be taught how to identify and clarify the differences between rules and character [21].

The themes of Pedagogy and Role Modeling describe how the learner needs to be familiarized with virtue and care ethics in healing with both knowledge and learning through observing. With the Pedagogy theme, some papers focus on the educational modalities such as utilizing virtues (specifically relating to roles) in ethical cases to improve understanding [24]. Some are specific on how to teach virtue ethics with extrapolations from nonmedical school environments to healthcare [17]. As noted previously, some believe that teaching by way of virtue ethics is better than that utilizing Principlism, and the former ought to be part of the medical curriculum [20]. This advocacy includes utilizing digital technologies to teach virtue ethics in healthcare environments [2]. Another suggested utilizing teaching strategies using care ethics to shift the focus from inner qualities to relational capacities, incorporating emotions and reason, promoting humanistic healing [11]. With the Role Modeling Theme, papers emphasized the essential aspect of role modelling to promote virtue and care ethics. To enhance virtue, improved role models are needed as well as literature that promotes examples of role models [14]. Narratives can help improve understanding of caring role modelling [6].

The theme of Relationships describes how virtue/care ethics are based upon the character-based interaction of two or more persons, although care ethics emphasizes the inequality of the relationship-based interaction. This theme notes how relationships foster care in medicine through humanistic practice in the caring endeavor [22]. Each practitioner needs to acknowledge how the enhancement of virtue ethics within oneself promotes the betterment of the patient [11]. Virtue and care may effectively be engaged through relationships not only with patients but also with their families to enhance compassion [7]. Patient-centered care implicitly requires a caring attitude towards patients. The role modeling relationship with teachers is thought to support this ethic [3, 14]. Humanistic teachers are influential in imparting care to their learners, and learners are drawn to them as role models of empathy and interpersonal communication [3]. Mentorship enhances care beyond one's medical training [8]. The relational nature of caring also emphasizes interpersonal aspects of 
emotion and competency [11]. Educational opportunities are recommended to promote humanism and professionalism to address challenging relationships with patients [14].

The theme of Praxis/Humanistic Behavior concerns the ways in which the learner may come to manifest humanistic behavior when incorporating the needed virtues and care in healing. Perhaps first described by Peabody nearly a century ago [48], virtue and care ethics act as a foundation to humanistic behavior and professionalism in patient care, promoting practice care particularly when achieved with clearly articulated objectives [11]. Outcomes include clarification of values and diversity of values and personal growth, promotion of caring attitudes, and meaningfulness of professionalism as valued endpoints $[3,19]$. The types of identified humanistic behavior in these 25 papers included: virtues of compassion, altruism, and self-awareness, and role-modeling by medical educators. These articles included such endpoints to evaluate humanism and professional identity formation as visual narratives that convey humanistic insights [1], Humanistic Practices Teaching Effectiveness Questionnaire [3], narrative-based professionalism portfolios [13], moral reasoning assignments [18], experience sampling methodology [20], how people act in experimental settings [20], and e-portfolios [8]. Other outcome attributes such as mindfulness, exceptional communication skills, and passion for care were also cited [8]. Additionally, there was a focus on how virtues such as compassion can be nurtured and thereby enhance the educational process and facilitate humanistic care to patients and their families [7].

The theme of Culture/Hidden Curriculum addresses how deleterious aspects of medical culture (through damaging moral conduct and toxic character) can upend humanistic educational efforts [15]. This theme describes the challenges of an adverse culture that can be hostile to virtue and care ethics. Medical training can be seen as a negative reinforcer of empathetic virtue [12]. As a result, there can be a noteworthy gap between the virtuous physician one aspires to be and the physician that one is, requiring that we incorporate aspects of pedagogy and role modeling to improve professional identity formation in recognizing the need for cultural change [14]. There can be many challenges in promoting virtue and care ethics given that we are human, so we must address the moral distress that occurs when we fall short of our aspirations [23].

The identified noteworthy considerations of professionalism, narrative, burnout prevention, and learning communities, can be interpreted as additional means to counter impediments that adversely influence the cultivation of humanistic behavior. Professionalism is relevant in this scoping review as the aspirational intent of virtue and care ethics are professional development to overcome the detractive aspects of medical education that negatively affect behavior. Professionalism is cited by many papers as an application of virtue ethics to the medical social contract, based on altruism and contract keeping [12]. Reflective exercises have been utilized to promote care and caring, resilience and wellness with the goal of becoming humanistic physicians [8]. Virtue ethics is seen as not only a basis for professionalism but also a means to professional formation [14]. Virtue ethics is seen as a means by which to foster ethical and professional educators [16]. The relationship between virtue ethics and professionalism helps to guide the learner highlighting the aspirations of character towards one's own moral development [23]. As there is an educational requirement for professionalism, cultivating appropriate virtue and care ethics promote patient care [16]. One paper cites "professional responsibility" as a virtue, playing a central role in the development of medical professionalism [10]. Compassionate care and professional identity that is respectful of patients promotes humanism, which is vital to the professionalism enterprise [14].

The consideration of Narrative describes the modality of teaching using narratives on physician virtues, motivations, and behavior looking at literature (rather than physician-life stories) to encourage compassion [13]. Others advocate personal medical narratives to enhance humanistic care [1], using stories told from the perspective of physicians and then applying a virtue framework to better understand the ethical aspects of character [25]. Narrative-based professionalism efforts are intended to promote integrity, empathy, and patient engagement while promoting compassionate and responsive professional identity [14]. Personal narrative as a reflective writing exercise has been used to enhance student resilience and improve mindfulness [8]. Another avenue of narrative has been the use of appreciative inquiry in writing narratives about influential teachers to promote excellence, self-awareness, encouragement, and role modeling [6].

The consideration of Prevention of Burnout specifically focuses on burnout prevention by focusing on relationships with patients, open discussions on burnout, and the challenges of suffering patients [5]. Learning Communities have been utilized to enhance role modelling of humanism and convey caring attitudes as part of faculty development across several medical schools [3]. That utility includes requisite faculty development to enhance mindfulness, humanism, and communication skills, as well as to concentrate on reflective learning in groups and enhance skill building and role modeling [6]. With medical students, efforts to foster altruism and 
compassion can enhance care and humanism toward patients [7].

When the articles were evaluated for relevant metaphors (Table 3), these cluster into two domains: Aspirational and Detractive. The Aspirational metaphors consist of care and virtue being "Habits of the heart," [18], that virtue was like "A beacon on a map," [23] and that one needed to push oneself as if "Learning to drive on the edge of the tires" [11]. The Detractive metaphors consist of how physicians can see themselves versus others as "Heroes vs. Villains," that physicians believe that they are in an "Ailing culture" and that narrative can assist in exploring the "gap between virtue and what we do" [13]. The utilization of ethics can be seen as a "Bludgeon," [12] and that the journey of becoming and being a physician can be one of "Medical Monasticism" (i.e., self-sacrifice) [23]. This analysis shows a deep tension in the literature on virtue and care ethics education. These thematic and metaphorical elements of the articles that we reviewed lend support to the idea, discussed below, that within the medical curriculum the efficacy of (and desire for) virtue and/or care ethics education is significantly tempered by systemic issues (especially mastery of medical information and procedures), which could hinder virtue development and role-modeling.

\section{Discussion}

This scoping review is innovative with a specific goal of identifying thematic connections between virtue and care ethics, medical education, and humanistic clinical practice. While virtue ethics goes back to the time of Plato and Aristotle [49], its Renaissance and then development within contemporary bioethics and inclusion into medical education has been going on for half a century. Further, care ethics, has been conceptualized over the last 40 years, and highlights "the relational, the local and the particular" [53]. As an ethical framework, its central concern is not the development of a systematic moral theory with generalizable rules and duties but at its core emphasizes human interdependence and inequality in caring relationships [31]. Despite the robust literature on these approaches to ethics, there has been a relative lack of articles that build upon aspects of virtue and/or care ethics towards health care curricular inclusion with

Table 3 Relevant Metaphors

\begin{tabular}{ll}
\hline Aspirational & Detractive \\
\hline "Habits of the heart" & $\begin{array}{l}\text { "Heroes vs. Villains" (Physicians vs. } \\
\text { Others) }\end{array}$ \\
"A beacon on a map" (Virtue) & "Ailing culture" \\
"Learning to drive on the edge of & "Bludgeon" of ethics \\
the tires" & "Medical Monasticism" (Self-Sacrifice) \\
\hline
\end{tabular}

an endpoint of humanistic behavior. What was learned in this study is that medical educators do have a small body of work that they can access to include these aspects of humanism in medical education [37]. This review had a noted limitation of a constricted size of citations, such that full text searching of abstracts was necessary (which reflects the late emergence of virtue and care ethics in medical education only over the past three decades). Also, we relied upon authors using the term humanism, care ethics, and virtue ethics so that manuscripts could be discovered in our search. Of note, when we attempted to use professionalism, it did not alter our results. Our resultant list of citations was from reputable journals of medical education and ethics and worth consideration for future curricular development. What we can hope for now is a growth of more peer-reviewed articles that flesh out understanding of virtue and care ethics and recognize their differences. That is, virtue ethics has a focus on the individual character of the physician, whereas care ethics highlights interdependence, which may foster communities of practice to support resilience and personal growth [32]. Such medical education curricula may utilize endpoints that bolster the professional growth of future physicians such that they will be the exemplars of humanistic care. Identifying useful methods of measuring or assessing humanistic care, beyond self-report, will be important to evaluate the resultant curricula. Further, this project may prove facilitative in the construct of model curricula in virtue and care ethics education to enhance learner humanism by using these and similar articles as a pedagogical resource.

\section{Conclusion}

This scoping review set out to evaluate publications in the medical literature that address aspects of virtue and care ethics in medical curricula toward the cultivation of learner humanism. We successfully found twenty-five papers that were relevant, of which eight had full implementation through curricula. The themes noted assist in understanding the many factors that play a role in using care and virtue ethics in curricula toward humanistic behavior. It is the intention of this working group to encourage others to initiate model curricula that play off the strengths of the results of this paper to translate virtue and care ethics into a curriculum that promotes humanistic behavior. These published resources and the present analysis of them may serve as a foundation for sound curriculum related to humanism. Implementation will assist in utilizing virtue and care ethics and promoting humanism among physicians.

Acknowledgements

The authors would like to acknowledge the efforts of Neil Farber, MD who contributed to the early phase of this project. 


\section{Authors' contributions}

$\mathrm{DD}, \mathrm{DO}, \mathrm{MD}, \mathrm{JDM}, \mathrm{BC}$, and NS all contributed to the writing of the main manuscript text, MD performed all library database searches, and DD prepared Fig. 1, and Tables 1, 2 and 3. All authors reviewed the manuscript. The author(s) read and approved the final manuscript.

\section{Authors' information}

David John Doukas, MD.

Dr. Doukas holds the James A. Knight Chair of Humanities and Ethics in

Medicine, is Professor of Family and Community Medicine at Tulane University School of Medicine, is Executive Director of the MS Program in Bioethics and Medical Humanities and directs the Program on Medical Ethics and Human Values. He is also the IntegratedEthics Program Officer at the Southeast Louisiana Veterans Health Care System, and Clinical Ethics Liaison, VISN 16, U.S. Department of Veterans Affairs. The contents do not represent the views of the Department of Veterans Affairs or the United States Government.

David T. Ozar, PhD.

David Ozar, Ph.D., is Emeritus Professor of ethics, social ethics, professional and health care ethics, Department of Philosophy, Loyola University Chicago, and an Affiliate Member of the Professional Staff and member and consulting ethicist on the Institutional Ethics Committee, NorthShore University Health System in Evanston IL.

Martina Darragh, MLS.

Ms. Darragh is a retired librarian, having served Georgetown University from 1993 to the end of 2018. Martina loved being a librarian and will volunteer at a local library once the pandemic is over.

Janet M. de Groot, MD, MMedSC.

Dr. de Groot is Professor of Psychiatry, Oncology and Community Health Sciences at the Cumming School of Medicine, University of Calgary. She is the co-lead of the Professionalism and Physician Health Program for the three-year MD program.

Brian S. Carter, MD.

Dr. Carter holds the Marjorie and William Sirridge Endowed Professorship in, and is Chairman of, the Department of Medical Humanities and Bioethics, and Professor of Pediatrics, in the School of Medicine where he directs the educational program in humanities and ethics in the 6-year combined BA/MD program.

Nathan Stout, PhD.

Dr. Stout is Lecturer in the Program for Medical Ethics and Human Values at Tulane University School of Medicine and serves as Medical Ethicist in the Southeast Louisiana Veterans Health Care System, U.S. Department of Veterans Affairs. The contents do not represent the views of the Department of Veterans Affairs or the United States Government.

\section{Funding}

This project was made possible with a Mapping the Landscape grant \# LR-17015 from the Arnold P. Gold Foundation Research Institute.

\section{Availability of data and materials}

The datasets used and/or analyzed during the current study are available from the corresponding author on reasonable request.

\section{Declarations}

Ethics approval and consent to participate

This project and manuscript do not involve human participants, human data, or human tissue, such that ethics approval and consent is not applicable.

\section{Consent for publication}

No individual person's data in any form (including any individual details, images, or videos) was used in this project of manuscript, therefore consent is not applicable.

\footnotetext{
Competing interests

David John Doukas, MD,

None.

David T. Ozar, PhD.

None.

Martina Darragh, MLS.
}

None

Janet de Groot, MD, MMedSc.

Professional Grants,

Understanding Educational Experiences across CSM: Informing Critical Indigenous Health Education Identified Education Need. Roach P (PI), co-I de Groot JM. Office of Health Medical Education Scholarship Research and Innovation grants, 2020-2021.

Preventing depression and enhancing preparation for end of life among individuals with advanced cancer. Co-principal investigator. Alberta Cancer Foundation, 2020-2021.

Confronting the reality of racism that Indigenous Canadians experience in healthcare: A video and simulation project to spur decolonization in medical education. University of Calgary li'tah'poh'to'p Indigenous Strategy Grant. de Groot JM (PI), 2019-2020.

Brian S. Carter, MD.

None.

Nathan Stout, PhD.

None.

\section{Author details}

${ }^{1}$ Department of Family and Community Medicine, James A. Knight Chair of Humanities and Ethics in Medicine, Program in Medical Ethics and Human Values, Tulane University School of Medicine, 1430 Tulane Ave, \#8033, New Orleans, LA, USA. ${ }^{2}$ Loyola University, Chicago, USA. ${ }^{3}$ Georgetown University, Washington, USA. ${ }^{4}$ University of Calgary, Calgary, CA, Canada. ${ }^{5}$ University of Missouri-Kansas City, Kansas City, USA.

Received: 5 October 2021 Accepted: 24 November 2021

Published online: 26 February 2022

\section{References}

Virtue/Care/Humanism Resultant Publications (Bolded citations contain all three factors sought: Definition, Curriculum Implementation, and Humanism Evidenced)

1. Arnold BL, Lloyd LS, von Gunten CF. Physicians' reflections on death and dying on completion of a palliative medicine fellowship. J Pain Symptom Manag. 2016;51(3):633-9.

2. Bolsin S, Faunce T, Oakley J. Practical virtue ethics: healthcare whistleblowing and portable digital technology. J Med Ethics. 2005;31(10):612.

3. Branch WT Jr, Frankel R, Gracey CF, Haidet PM, Weissmann PF, Cantey $P$, et al. A good clinician and a caring person: longitudinal faculty development and the enhancement of the human dimensions of care. Acad Med. 2009;84(1):117-25.

4. Cook T, Mavroudis CD, Jacobs JP. Respect for patient autonomy as a medical virtue. Cardiol Young. 2015;25(8):1615-20.

5. Kesselheim JC, Atlas M, Adams D, Aygun B, Barfield R, Eisenman $\mathrm{K}$, et al. Humanism and professionalism education for pediatric hematology-oncology fellows: a model for pediatric subspecialty training. Pediatr Blood Cancer. 2015;62(2):335-40.

6. Osterberg L, Swigris R, Weil A, Branch WT Jr. The highly influential teacher: recognising our unsung heroes. Med Educ. 2015;49(11):1117-23.

7. Schaechter JL, Canning EH. 'Pals'. A medical student public service program. West J Med. 1994;161(4):390-2.

8. Wald HS, Anthony D, Hutchinson TA, Liben S, Smilovitch M, Donato AA. Professional identity formation in medical education for humanistic, resilient physicians: pedagogic strategies for bridging theory to practice. Acad Med. 2015;90(6):753-60.

The following publications contain two of the three factors sought

9. Austin W. The terminal: a tale of virtue. Nurs Ethics. 2007;14(1):54-61.

10. Barilan YM. Responsibility as a meta-virtue: truth-telling, deliberation, and wisdom in medical professionalism. J Med Ethics. 2009;35(3):153-8.

11. Benner P. A dialogue between virtue Ethics and care Ethics. Theor Med. 1997;18:47-61. 
12. Brody H, Doukas D. Professionalism: a framework to guide medical education. Med Educ. 2014;48(10):980-7.

13. Coulehan J. Written role models in professionalism education. Med Humanit. 2007:33(2):106-9.

14. Coulehan J. Viewpoint: today's professionalism: engaging the mind but not the heart. Acad Med. 2005;80(10):892-8.

15. Coulehan J, Williams PC. Vanquishing Virtue: The Impact of Medical Education. Acad Med. 2001;76(6):598-605.

16. Doukas DJ. Where is the virtue in professionalism? Camb Q Healthc Ethics. 2003;12(2):147-54

17. Gould JB. Better hearts: teaching applied virtue Ethics. Teach Philos. 2002;25(1):1-26.

18. Irby DM, Hamstra SJ. Parting the clouds: three professionalism frameworks in medical education. Acad Med. 2016;91(12):1606-11.

19. Kopelman LM. Values and virtues: how should they be taught? Acad Med. 1999:74(12):1307-10.

20. Kotzee B, Ignatowicz A. Measuring 'virtue' in medicine. Med Health Care Philos. 2016:19(2):149-61.

21. Leffel GM, Oakes Mueller RA, Curlin FA, Yoon JD. Relevance of the rationalist-intuitionist debate for ethics and professionalism in medical education. Adv Health Sci Educ Theory Pract. 2015;20(5):1371-83.

22. Madani M, Larijani B, Madani E, Ghasemzadeh N. Establishment of medical education upon internalization of virtue ethics: bridging the gap between theory and practice. J Med Ethics Hist Med. 2017:10:3.

23. McCammon SD, Brody H. How virtue ethics informs medical professionalism. HEC Forum. 2012;24(4):257-72.

24. McDougall R. Understanding doctors' ethical challenges as role virtue conflicts. Bioethics. 2013;27(1):20-7.

25. Toon P. Setting boundaries: a virtue approach to the clinician-patient relationship in general practice. In: Bowman D, Spicer J, editors. Primary Care Ethics. New York: Radcliffe Pub; 2007. p. 83-99.

\section{Reference list}

26. Atkins S, Lewin S, Smith H, Engel M, Fretheim A, Volmink J. Conducting a meta-ethnography of qualitative literature: lessons learnt. BMC Med Res Methodol. 2008:8:21.

27. Beauchamp TL, Childress JF. Principles of biomedical Ethics. 8th ed. New York: Oxford University Press; 2019.

28. Britten N, Campbell R, Pope C, Donovan J, Morgan M, Pill R. Using meta ethnography to synthesize qualitative research: a worked example. J Health Serv Res Policy. 2002;7(4):209-15.

29. Carrese JA, Malek J, Watson K, Lehmann LS, Green MJ, McCullough LB, et al. The Romanell report: the essential role of medical Ethics education in achieving professionalism. Acad Med. 2015;90(6):744-52.

30. Churchill LR. Damaged humanity: the call for a patient-centered medical ethic in the managed care era. Theor Med. 1997;18(1-2):113-26.

31. Delgado J, de Groot JM, McCaffery G, Dimitropoulos G, Sitter K, Austin W. Communities of practice: acknowledging vulnerability to improve resilience in healthcare teams. J Med Ethics. 2020;47:488-93.

32. Delgado J, Siow S, de Groot JM, McLane M, Hedlin M. Towards collective moral resilience: the potential of communities of practice during the Covid-19 pandemic and beyond. J Med Ethics. 2021:47:374-82.

33. Doukas DJ, Kirch DG, Barzansky BTP, BM, Wear S, Carrese JA, Fins JJ, Lederer LL. Perspective: transforming educational accountability in medical Ethics and humanities education toward professionalism. Acad Med. 2015:90(6):738-a743.

34. Doukas DJ, McCullough LB, Wear S. Medical education in medical Ethics and humanities as the Foundation for Developing Medical Professionalism. Acad Med. 2012:87(3):334-41.

35. Doukas DJ, McCullough LB, Wear S, Lehmann LS, Nixon LL, Carrese JA, et al. The challenge of promoting professionalism through medical Ethics and humanities education. Acad Med. 2013;88(11):1624-9.

36. Driver J. Consequentialism and Feminist Ethics. Hypatia. 2005;20(4):183-99.

37. Gaufberg E. Mapping the landscape, journeying together: the Gold Foundation's model for research-based advocacy for humanism in medicine. Acad Med. 2017:92:1671-3.

38. Gold Foundation, https://www.gold-foundation.org/definition-of-human ism/, Accessed, 24 Apr 2020
39. Groenhout R. Chapter 22. Virtue and a feminist ethics of care. In Timpe K, Boyd CA (Eds.). Virtues and their vices. Oxford scholarship online; 2014. https://doi.org/10.1093/acprof:oso/97801099645541.003.0023.

40. Held V. the ethics of care as moraltheory. Chapter in: V. Held, The Ethics of Care: Personal, Political and Global. Oxford Scholarship Online; 2006. https://doi.org/10.1093/0195180992.001.0001.

41. Hursthouse, Rosalind and Glen Pettigrove, Virtue Ethics, in The Stanford Encyclopedia of Philosophy (Winter 2018 Edition), Edward N. Zalta (ed.), URL $=<$ https://plato.stanford.edu/archives/win2018/entries/ ethics-virtue/>.

42. Leget C, van Nistelrooij I, Visse M. Beyond demarcation: care ethics as a necessary field of inquiry. Nurs Ethics. 2019;26:17-25.

43. Levac D, Colquhoun H, O'Brien KK. Scoping studies: advancing the methodology. Implement Sci. 2010;5:69. https://doi.org/10.1186/ 1748-5908-5-69.

44. Liaison Committee on Medical Education (LCME). Functions and structure of a medical school: standards for accreditation of medical education programs leading to the MD degree, https://lcme.org/publications/ Publication Date: March 2020, Accessed July 14, 2021.

45. Maio G. Fundamentals of an Ethics of care. In: Krause F, Boldt J, editors, Care in Healthcare. Palgrave Macmillan, Cham; 2018. https://doi.org/10. 1007/978-3-319-61291-1 4.

46. Miles A. Science, humanism, judgement, ethics: person-centered medicine as an emergent model of modern clinical practice. Folia Med. 2013;55(1):5-24.

47. Ozar D, Agris J, Brody H, Doukas DJ, Green, MJ, Harter, T, et al. APHC task force on professionalism: APHC white paper on professionalism and professionalism education; 2019. https://academy-professionalism.org/ content.aspx?page_id=86\&club_id=625584, Accessed 12 May 2020.

48. Peabody FW. The care of the patient. JAMA. 1927;88:877-82.

49. Pellegrino ED, Thomasma DC. The virtues in medical practice. New York: Oxford University Press; 1993.

50. Slote M. The Ethics of care and empathy: Routledge; 2007.

51. Tronto JC. Moral boundaries: a political argument for an ethic of care. New York: Routledge; 1993.

52. Van Der Graaf R, Van Delden JJ. Clarifying appeals to dignity in medical ethics from an historical perspective. Bioethics. 2009;23(3):151-60.

53. Vosman F, Niejmeijer A. Rethinking critical reflection on care: late modern uncertainty and the implications for care ethics. Med Health Care and Philos. 2017:20:465-76

54. Weisberg DF. Science in the service of patients: lessons from the past in the moral battle for the future of medical education. Yale J Biol Med. 2014;87(1):79-89.

\section{Publisher's Note}

Springer Nature remains neutral with regard to jurisdictional claims in published maps and institutional affiliations.

Ready to submit your research? Choose BMC and benefit from

- fast, convenient online submission

- thorough peer review by experienced researchers in your field

- rapid publication on acceptance

- support for research data, including large and complex data types

- gold Open Access which fosters wider collaboration and increased citations

- maximum visibility for your research: over 100M website views per year

At BMC, research is always in progress.

Learn more biomedcentral.com/submissions 